\title{
Estimation of the pH of soybean rhizoplane, rhizosphere and bulk soil and its effect on availability and uptake of phosphorus in calcareous Vertisols
}

\author{
Urwashi Manekar*, Tirunima Patle, S.K. Sharma and Ranjeet \\ Department of Soil Science and Agricultural Chemistry, College of Agriculture, Indore (M.P.) India \\ (Email: urvashi14manekar1992@gmail.com)
}

\begin{abstract}
Vertisols are spread over central and western parts in Madhya Pradesh in India.As the Vertisolsare calcareous and/or alkaline in nature, mobility of $\mathrm{P}$ from soil to root surface is carried by diffusion process, and this diffusion rate is quite low i.e. $0.13 \mathrm{~mm} \mathrm{day}^{-1}$ (Jungk 1991). One of the major limitation is thatmany rhizosphere chemical interactions that can be involved in the changes ofP ion concentration in the soil solution and in the replenishment of the depleted soil solution ( $\mathrm{P}$ buffering capacity)do not taken into account (Darrah, 1993).This prompted us to re-evaluate the P-fertility of Vertisols. In the study an attempt has been made to evaluate the most suitable method for $\mathrm{P}$ availability in calcareous Vertisols for crops considering the $\mathrm{pH}$ of rhizosphere. By agar plate technique, the $\mathrm{pH}$ of rhizoplane and rhizoplane soil was found acidic even though soil $\mathrm{pH}$ was7.6. The major portion of inorganic $\mathrm{P}$ in Vertisols is associated with $\mathrm{Ca}(\mathrm{Ca}-\mathrm{P})$, which can be soluble more under acid condition than $\mathrm{pH} 8.5$ of Olsen's condition. The $\mathrm{pH}$ of bulk soil, that is unplanted soil which is treated in same way of applied nutrient and water as the planted pots, is 7.9. Soybean crop decreased the $\mathrm{pH}$ of rhizosphere and rhizoplane by 7.5 and 6.0 respectively. Following the various crops the $\mathrm{pH}$ of rhizosphere decreased. Among various crops tested the lowest $\mathrm{pH}$ (5.8) of the rhizosphere and rhizoplane -attached soil was noticed in care of Chickpea. In case of pea, maize, sorghum and wheat the $\mathrm{pH}$ of rhizosphere and rhizoplane were 7.4 and 6.1, 7.6 and 6.4, 7.5 and 6.4, 7.5 and 6.3, respectively. Decreased $\mathrm{pH}$ due to rhizosphere can dissolve the phosphorus from the Calcium and increase the availability of $\mathrm{P}$ in Calcareous/ Alkaline soil.
\end{abstract}

Key Words : pH of soybean, Rhizoplane, Rhizosphere, Bulk soil, Phosphorus in calcareous Vertisols

View Point Article : Manekar, Urwashi, Patle, Tirunima, Sharma, S.K. and Ranjeet (2021). Estimation of the pH of soybean rhizoplane, rhizosphere and bulk soil and its effect on availability and uptake of phosphorus in calcareous Vertisols. Internat. J. agric. Sci., 17 (AAEBSSD) : 229-232, DOI:10.15740/HAS/IJAS/17-AAEBSSD/229-232. Copyright@2021: Hind Agri-Horticultural Society.

Article History : Received : 27.07.2021; Revised : 30.07.2021; Accepted : 02.08.2021

\section{INTRODUCTION}

Plant uptake of $\mathrm{P}$ from soil is a complicated process, in which P moves to the root surface form P pool fixed on soil particles with an extremely small diffusion coefficient of approximately $0.13 \mathrm{~mm} \mathrm{day}^{-1}$ (Jungk et al., 1991). Due to of the small diffusion rate, $\mathrm{P}$ uptake by crop species is proportional to the surface area of roots, including root hairs (Itoh and Barber, 1983). Hence, the $\mathrm{P}$ absorption by plant roots originates from the rhizosphere, which consists of the soil surrounding the roots at the thickness of approximately 1.0-2.0 mm

\footnotetext{
*Author for correspondence:
} 
(Youssef and Chino, 1990; Dotaniya and Meena 2015). The $\mathrm{pH}$ levels of rhizosphere are often observed to be 1-2 units lower than that of bulk soil because of acidification by root exudates, such as organic acid (Riley and Barber 1971; Gahoonia et al., 1992; Li et al., 2007). This indicates that the $\mathrm{pH}$ level of vertisols changes from the original alkaline level, between 7.5 and 8.5, to neutral and acidic in rhizosphere, particularly on the rhizoplane and root surface. Thus, root acidification of the rhizosphere in the vertisols could possibly solubilize increased amounts of $\mathrm{P}$ from the soil than those estimated by the Olsen method, using an alkaline extractant at $\mathrm{pH}$ 8.5. However, few studies have investigated the acidification of the rhizosphere of various crop species grown on vertisols, and compared soil test results using different extractants for an improved accuracy of estimation of available $\mathrm{P}$ in vertisols.

\section{Material AND Methods}

The insitu experiment was conducted in the Net House of AICRP on Salt Affected Soils, College of Agriculture, Indore. To examined acidification in rhizosphere, six different crop species chickpea (Cicer arietinum) JG-21, pea (Pisum sativum) Arkel, maize (Zea Mays) JM-13, soybean (Glycine max) JS 95-60, sorghum (Sorghum vulgare), wheat (Triticum aestivum) JW-7, were grown in different pots. Vertisols soil of western Madhya Pradesh was used in this examination and growing period of crops were two month. For this experiment $1 \mathrm{~kg} \mathrm{pot}^{-1}$ soil was taken andexamined the $\mathrm{pH}$ of the initial soil sample which was 7.8. The essential nutrients were supplied through dilute solution (Hoagland and Arnon, 1950). Blank soil (without crop) was also kept as control in pot for comparison. Rhizosphere soil have roots of crop, which were gently or vigorously shaken to release loosely or more tightly attached soil and remaining soil on the roots after vigorous shaking was considered as rhizoplane-attached soil. These fractions, including the bulk soil, were placed in distilled water and measured the soil $\mathrm{pH}$ with the help of HORIBA twin $\mathrm{pH}$ meter. To estimatethe $\mathrm{pH}$ of root surface, agar plate method as described by Hausslinget. al., 1985 was used.Seeds were sown in paper glass filled with sand. Roots of 12 days old seedlings of different crops were removed carefully without damage and placed on agar plates containing one of the $\mathrm{pH}$ indicators i.e. Bromcresol purple ( $\mathrm{pH} 5.2$ purple- $\mathrm{pH} 6.8$ yellow) or Bromcresol green ( $\mathrm{pH} 3.8$ yellow- $\mathrm{pH} 5.2$ blue) or Bromthymol blue ( $\mathrm{pH} 6.0$ yellow- $\mathrm{pH} 7.6$ blue) or Methyl red (pH 4.4 red- $\mathrm{pH} 6.2$ yellow).

\section{RESUlTs AND Discussion}

The results obtained from the present investigation as well as relevant discussion have been summarized under following heads :

\section{pH of rhizosphere soil and its roots surface (rhizoplane) :}

The results shows that acidification of the rhizosphere soil by the roots of various crop species as compared to bulk soil as change in $\mathrm{pH}$ was observed. The $\mathrm{pH}$ of bulk soil, that is unplanted which is treated in same way of applied nutrient and water as the planted pots, shows no change in $\mathrm{pH}$ i.e. it remains 7.9. Soybean crop decreases the $\mathrm{pH}$ in rhizosphere from 7.9 to 7.5 and in rhizoplane it became 6.0. Following the various crops the $\mathrm{pH}$ of rhizosphere shows reduction. Among various crops tested the lowest $\mathrm{pH}(5.8)$ in the rhizosphere and rhizoplane -attached soil was noticed in care of Chickpea. In case of pea, maize, sorghum and wheat the $\mathrm{pH}$ of rhizosphere and rhizoplane were 7.4 and 6.1, 7.6 and 6.4, 7.5 and 6.4, 7.5 and 6.3, respectively (Table 1). Decreased pH due to rhizosphere can dissolve the phosphorus from the Calcium and increase the availability of P in Calcareous/Alkaline soil. Decreased $\mathrm{pH}$ of soybean roots changed the colorof bromocresol

\begin{tabular}{|c|c|c|c|c|}
\hline \multirow{2}{*}{ Sr. No. } & \multirow{2}{*}{ Crop species } & \multicolumn{3}{|c|}{$\mathrm{pH}$} \\
\hline & & Bulk soil & Rhizosphere soil & Rhizoplane-attached soil \\
\hline 1. & Soybean & 7.9 & 7.5 & 6.0 \\
\hline 2. & Chickpea & 7.9 & 7.3 & 5.8 \\
\hline 3. & Pea & 7.9 & 7.4 & 6.1 \\
\hline 4. & Maize & 7.9 & 7.6 & 6.4 \\
\hline 5. & Sorghum & 7.9 & 7.5 & 6.4 \\
\hline 6. & Wheat & 7.9 & 7.5 & 6.3 \\
\hline
\end{tabular}




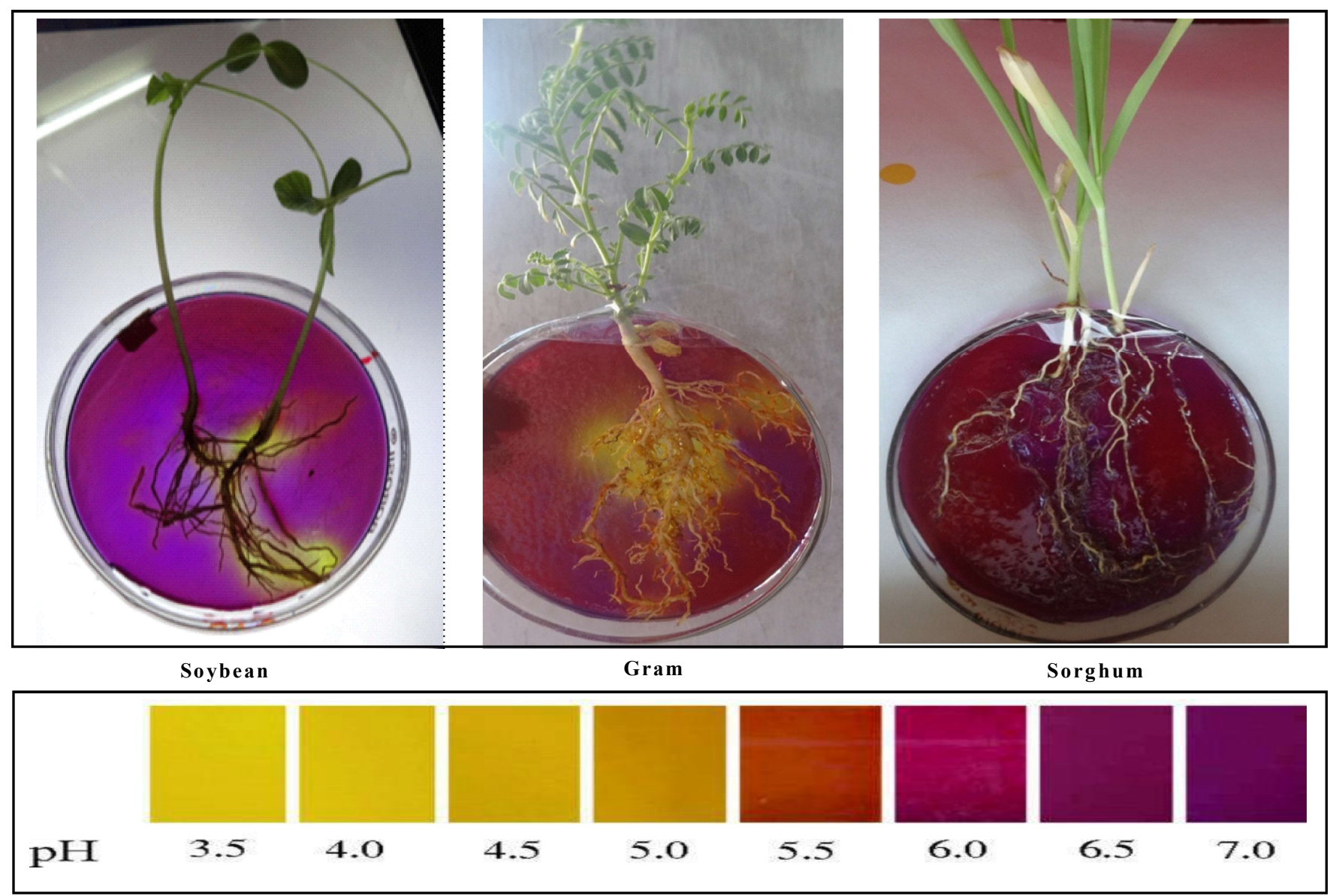

The roots were imbedded for $6 \mathrm{~h}$ in agar gel containing a $\mathrm{pH}$ indicator (Bromocresol Purple). Yellow indicates acidification and purple indicates alkalization

from purple to yellow, thus rhizoplane $\mathrm{pH}$ appeared to be in the range of 6.8-5.2.

The non-response of $\mathrm{P}$ application on growth and yield of soybean can be explained on the basis of the $\mathrm{pH}$ of rhizhosphere and rhizoplane which is acidic in nature (Table 1). Decreased pH due to rhizosphere can dissolve the phosphorus from the Calcium and increase the availability of P in Calcareous/ Alkaline soil (Ae et al., 1991, Li et al., 1997, Neumann et al., 1999). This might be the possible reason for non- response of $\mathrm{P}$ application to soybean in these calcareous Vertisols. Further, Many researchers (Riley and Barber, 1971, Gahoonia et al., 1992, Li et al., 2007) showed that the $\mathrm{pH}$ of the rhizosphere soil is 1-2 unit lower then bulk soil and that difference of $\mathrm{pH}$ enhances the solubility of phosphorus from the fixed Ca-P in Vertisols and associated soil (Neumann and Romheld, 1999). Soybean crop decreased the $\mathrm{pH}$ in rhizosphere 7.5 and rhizoplane 6.0.Decreased $\mathrm{pH}$ of soybean roots changed the colour of bromothymol blue and bromocresol purple, but did not detectably change the colour of the two indicators (methyl red and bromocresol green). Thus rhizoplane $\mathrm{pH}$ appeared to be in the range of 6.0-5.2 (Plate 1). The results indicated that the $\mathrm{pH}$ values decreased near the roots in soils with a $\mathrm{pH}$ of the bulk soil (about 7.0). Changes of $\mathrm{pH}$ were as much as 2 units as compared to the bulk soil. Conversely, the rhizosphere $\mathrm{pH}$ decreased by about 2 units in soils with a bulk soil $\mathrm{pH}$ of 7. A slight decrease in the rhizosphere $\mathrm{pH}$ was observed in soils with a bulk soil $\mathrm{pH}$ of 8.4. The ability of soybean roots to influence the $\mathrm{pH}$ was larger than that of barley.

\section{Conclusion:}

These results also agree with the findings of Neumann and Romheld (1999) who reported that some plant species/genotypes release protons into the soil to acidify the rhizosphere condition to enhance P uptake from acid-soluble $\mathrm{Ca}$ phosphate. Following the various 
crops taken under study shows reduction in the $\mathrm{pH}$ of rhizosphere.Decreased $\mathrm{pH}$ of rhizosphere can dissolve the phosphorus from the Calcium-P and increase the availability of P in Calcareous/ Alkaline soil.On the basis of Agar plate method the rhizoplane $\mathrm{pH}$ of soybean appeared to be in the range of 6.0-5.2. Though the soils calcareous alkaline even than the $\mathrm{pH}$ of root surface was below 5.5 and in attached soil it might also be lower.

\section{REFERENCES}

Bray, R.H. and Kurtz, L.T. (1945). Determination of total, organic, and available forms of phosphorus in soils. Soil Sci., 59: 39-45.

Darrah, P.R.(1993). Therhizosphereandplant nutrition: A quantitative approach. Plant Soil, 155/156 : 1-20.

Gahoonia, T.S., Claassen, N. and Jungk, A. (1992). Mobilization of phosphate in different soils by ryegrass supplied with ammonium or nitrate. Plant Soil,140: 241-248.

Gillespie, A.R. and Pope, P.E.(1989). Alfalfa N2-fixation enhances the phosphorus uptake of walnut in inter plantings. Plant Soil,113: 291-293.

Haussling, M., Leisen, E., Marschner, H. and Romheld, V. (1985). An improved method for non descriptive measurement of the $\mathrm{pH}$ at the root soil interface (rhizosphere). J.Plant Physiol.,117: 371-375.

Jungk, A.O. (1991). Dynamics of nutrient movement at the soil-root interface, Plant Roots: the Hidden Half, (WAISEL, Y., et al., Eds.), Marcel Dekker, New York. pp455-481.
Jungk, A. and Claassen, N. (1997). Ion diffusion in the soilroot system. Adv. Agron., 61 : 53-110.

Li. L., Li, S.M., Sun, J.H., Zhou, L.L., Bao, X.G., Zhang, H.G., and Zhang, F.S. (2007). Diversity enhances agricultural productivity via rhizosphere phosphorus facilitation on phosphorus-deficient soils. Proc. Natl. Acad. Sci., 104: 1119211196.

Mehlich, A.(1984). Mehlich 3 soil test extractant: A modification of the Mehlich 2 extractant. Communication in Soil Sci. Pl. Analysis, 15: 1409-1416.

Neumann, G. and Romheld, V. (1999). Root excretion of carboxylic acids and protons in phosphorus-deficientplants. J. Plant Soil., 211: 121-130.

Olsen, S.R., Cole, C.V., Watanabe, F.S. and Dean, L.A.(1954). Estimation of available phosphorus in soil by extraction with sodium bicarbonate. U.S. Deptt. of Agri. circular 939. Washington D.C. USA:U.S. Govt. Printing office. pp. 19.

Riley, D. and Barber, S.A. (1971). Effect of ammonium and nitrate fertilization on phosphorus uptake as related to rootinduced $\mathrm{pH}$ changes at the root-soil interface. Soil Sci. Soc. Am. Proc., 35: 301-306.

Romheld, V., Muller, C. and Marschner, H.(1984). Localization and capacity of proton pumps in roots of intact sunower plants. Plant Physiol., 76 : 603-606.

Youssef, R.A. and Chino, M. (1989). Root-induced changes in the Rhizosphere of plant. Japanease Soc. Soil Sci. Plant Nutri., 35 (3): 461-468.

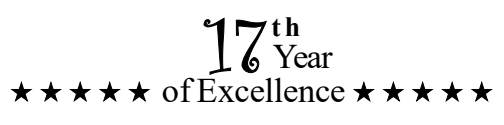

